\title{
Type 2 diabetes mellitus and colorectal neoplasia risk in Hispanics: A case-control study
}

\author{
Yaritza Díaz-Algorri, M.S., DrPH ${ }^{1}$, María Eugenia Lozada, B.S. ${ }^{1}$, Sofía M. López, B.S. ${ }^{1}$, \\ Carlos E. Bertrán-Rodríguez, B.S. ${ }^{1}$, Cinthia M. González-Hernández, B.S. ${ }^{1}$, Dilka González, \\ M.D. ${ }^{2}$, Cynthia M. Pérez-Cardona, Ph.D. ${ }^{4}$, Jessica Hernández, MSN ${ }^{1}$, Carmen Pedrosa, B.S. \\ ${ }^{2}$, Doris H. Toro, M.D. ${ }^{2}$, María González-Pons, Ph.D. ${ }^{1,3}$, and Marcia Cruz-Correa, M.D. Ph.D. \\ $1,2,3$ \\ ${ }^{1}$ University of Puerto Rico Comprehensive Cancer Center, PMB 711 Ave. 89 Ste. 105, San Juan, \\ P.R. 00927-6346 \\ 2VA Caribbean Healthcare System Casia \# 10 San Juan, P.R. 00921-3201 \\ ${ }^{3}$ University of Puerto Rico School of Medicine PO Box 365067 San Juan, P.R. 00936-5067 \\ ${ }^{4}$ University of Puerto Rico Graduate School of Public Health PO Box 365067 San Juan, P.R. \\ 00936-5067
}

\section{Abstract}

Aims-There is inconclusive evidence regarding the potential link between diabetes mellitus (DM) and colorectal cancer (CRC). Associations between type $2 \mathrm{DM}$ and colorectal neoplasia (CRN; colorectal cancer and/or adenomas) have not been well studied in Hispanics, an ethnic minority at high risk for type $2 \mathrm{DM}$. This study aims to determine the association between type 2 DM and CRN in Hispanics.

Methods-Hispanics with incident CRN and colonoscopy-negative controls from 2005-2009 were evaluated. Diagnosis of type $2 \mathrm{DM}$ was established by previous medical diagnosis and/or use of DM treatments. Unconditional logistic regression was performed to estimate odds ratios for the association between type $2 \mathrm{DM}$ and CRN.

Results-A total of 451 participants (mean age $61.1 \pm 11.9$ years, $59.6 \%$ men) were evaluated (218 with incident CRC, 77 with colorectal adenomas, and 156 colonoscopy-negative controls). The prevalence of type $2 \mathrm{DM}$ in this study was $25.1 \%$. After adjusting for potential confounding variables, women with type 2 DM were 2.74 (95\% CI: 0.94-7.99) times more likely to have CRN

(C) 2015 Published by Elsevier Inc.

Corresponding author: Dr. Marcia Cruz-Correa, University of Puerto Rico Comprehensive Cancer Center, PMB 711 Ave. 89 Ste. 105, San Juan, P.R. 00927-6346, marcia.cruz1@ upr.edu, Telephone: +1-787-772-8300 extension 1221, Fax: +1-787-522-3282.

Financial disclosures: No financial interests to disclose.

The contents of this manuscript do not represent the views of the VA Caribbean Healthcare System, the Department of Veterans Affairs or the United States Government.

Publisher's Disclaimer: This is a PDF file of an unedited manuscript that has been accepted for publication. As a service to our customers we are providing this early version of the manuscript. The manuscript will undergo copyediting, typesetting, and review of the resulting proof before it is published in its final citable form. Please note that during the production process errors may be discovered which could affect the content, and all legal disclaimers that apply to the journal pertain. 
and 4.83 times more likely to present with proximal colonic CRN (95\% CI: $1.25-18.58$ ) than women without type $2 \mathrm{DM}$. No statistically significant associations were found between type 2 DM and CRN among men.

Conclusions-An increased risk for CRN and proximal location of CRN was observed among Hispanic women with type 2 DM. Since DM is a highly prevalent disease in this population, adherence to routine CRC screening is of outmost importance.

\section{Keywords}

type 2 diabetes; type $2 \mathrm{DM}$; colorectal neoplasia; colorectal cancer; colorectal adenomas; Hispanics

\section{Introduction}

Colorectal cancer (CRC) is the $2^{\text {nd }}$ leading cause of cancer death in the United States (US). ${ }^{1}$ In Puerto Rico (PR), it is the $2^{\text {nd }}$ most commonly diagnosed cancer and the leading cause of cancer death among men and women. The age-adjusted CRC incidence rate from 20062010 was 52.0 and 34.8 per 100,000 men and women, respectively. ${ }^{2}$ Age-adjusted mortality rates during this period were 21.0 per 100,000 men and 13.0 per 100,000 women. ${ }^{2}$ Diabetes mellitus (DM) is a common cause of morbidity and mortality both in the US and PR. According to the Behavioral Risk Factor Surveillance System (BRFSS), the prevalence of DM in the US during 2010 was $8.7 \%$ (9.0\% in men and $8.7 \%$ in women). ${ }^{3}$ However, the prevalence of DM in PR during the same year was $12.8 \%$ (12.1\% in men and $13.4 \%$ in women) showing that there is a higher burden of this disease among Puerto Rican Hispanics $(\mathrm{PRH})^{3}$.

Studies have reported inconclusive results on the association between DM and CRC. . $^{4-7}$ Individuals with DM have been reported to have a 30-60\% increased risk of developing CRC compared to people without DM. ${ }^{4}{ }^{8}$ A possible explanation for the observed association between DM and CRC may be related to dietary patterns and sedentary lifestyles resulting in increased insulin levels, which may in turn stimulate the growth of colorectal tumors. ${ }^{9}, 10$ Type 2 DM and CRC share multiple modifiable risk factors including: highenergy intake, high animal fat intake, elevated consumption of refined carbohydrates, and elevated body mass index (BMI). These factors have also been associated with insulin resistance and hyperinsulinemia. ${ }^{11}$ Hyperinsulinemia can occur either endogenously, due to insulin resistance during the early stages of DM, or exogenously as a result of insulin administration or insulin secretagogues. ${ }^{11}$

Most of the studies that have evaluated the association between type 2 DM and CRC have been performed in Caucasian and Asian populations. The data available on Hispanic populations, including PRH, is limited. We hypothesized that individuals with type $2 \mathrm{DM}$ have an increased odds of colorectal neoplasia (adenomas and CRC; CRN) compared to those without type $2 \mathrm{DM}$. In this study, we pooled data from three studies to assess the association between type $2 \mathrm{DM}$ and CRN and to examine this association by neoplasia subsite while controlling for potential confounding factors. Confirmation of DM as a risk 
factor for CRN may have important implications for CRC screening strategies, especially in $\mathrm{PR}$ where the prevalence of DM is high and adherence to CRC screening is low.

\section{Materials and methods}

\subsection{Study population}

This analysis was based on pooled data from three IRB-approved studies in two study centers: the VA Caribbean Healthcare System and the Puerto Rico Medical Center facilities. Data from the following studies was included in our analysis: Type 2 DM and CRN Risk in Hispanics: A Case-Control Study (51 cases and 78 controls), Epidemiology of Loss of Imprinting (LOI) in Colorectal Cancer (164 cases and 77 controls), and Familial Colorectal Cancer in Puerto Rico: A Feasibility Study (80 cases and 1 control). Study participants included in this study were individuals with medical and pathological information up to October 11, 2011. Informed consent was obtained from all participants.

Study participants visited the designated study centers for colonoscopies due to routine screening, symptoms, and/or referrals by gastroenterologists and colorectal surgeons. A total of 1,045 participants older than 21 years were recruited; 451 subjects were included in the study (156 controls, 77 adenomas, and 218 CRC) and 594 were excluded. Cases must have had a CRN diagnosis confirmed by biopsy during the study period from January 1, 2005 to December 31, 2009. Control subjects were individuals without a personal history of CRN and a normal result in the colonoscopy and/or surgery reports. CRN was defined as cancer or adenomas of any size with serrated, tubular, villous, or tubulovillous features.

Cases and controls were recruited consecutively using convenience sampling. All participants included in this analysis were Hispanics as defined by the participant's selfreported heritage, lineage or place of birth. We excluded the following participants: diagnosis date outside of the 2005-2009 study period ( $n=119)$; recruitment colonoscopy date outside the 2005-2009 study period ( $\mathrm{n}=15)$; genetic syndrome diagnosis (including relatives) ( $\mathrm{n}=77)$; possible genetic syndrome diagnosis (including relatives) $(\mathrm{n}=93)$; diagnosed with other cancers $(\mathrm{n}=82)$; incomplete data and/or no pathological documentation $(\mathrm{n}=186)$; incomplete colonoscopy $(\mathrm{n}=10)$; colitis $(\mathrm{n}=3)$; non-Hispanic origin $(\mathrm{n}=3)$; no information of DM $(n=4)$; and age at diagnosis of DM ( $<25$ years) $(n=2)$. Epidat 3.1 (Xunta de Galicia, Pan American Health Organization and World Health Organization) was used to estimate the sample size needed $(\mathrm{n}=520)$ for a case-control study to detect the association using the following parameters: a 1:1 control:case ratio, an estimated odds ratio (OR) of $2.0,6,7$ an estimated prevalence of DM in the control group of $12.4 \%,{ }^{12}$ a significance level of $5 \%$, and a statistical power of $80 \%$.

\subsection{Variables}

Medical history, colonoscopy and pathology reports were obtained from medical records. Colonoscopy reports provided information regarding the presence of colorectal polyps and/or cancer (size, number, location, and appearance), completeness to cecum, and bowel preparation at the time of the procedure. Information regarding CRN location and histological type was obtained from pathology reports. For this analysis, CRN locations were classified as proximal colon (cecum, ascending colon, hepatic flexure, and transverse 
colon) or distal colon (splenic flexure, descending colon, sigmoid colon, recto-sigmoid junction, and rectum). Diagnosis of type $2 \mathrm{DM}$ was established by previous medical diagnosis and/or use of DM treatments. Similar to Flood et al., ${ }^{13}$ diagnosis of DM before age 25 was considered type $1 \mathrm{DM}$ and all others type $2 \mathrm{DM}$.

The Collaborative Family Registries for Colorectal Cancer (Colon CFR) questionnaire was used to obtain sociodemographic and clinical data from study participants. ${ }^{14}$ The following variables were analyzed: gender (male vs. female), median age ( $<61$ years vs. $\geq 61$ years), education ( $<12$ years vs. $\geq 12$ years), health insurance (public vs. private/Medicare), marital status (married vs. unmarried), type 2 DM diagnosis (yes vs. no), family history of DM (yes vs. no), and family history of CRC (yes vs. no). The lifestyle characteristics analyzed included: fruit intake ( $<1$ time/week, 2-4 times/week, and $\geq 5$ times/week), dark green leafy vegetable intake ( $<1$ time/week, 2-4 times/week, and $\geq 5$ times/week), meat intake $(<1$ time/ week, 2-4 times/week, and $\geq 5$ times/week), use of fiber supplements (yes vs. no), aspirin use ( $<3$ times/week vs. 33 times/week), non-steroidal anti-inflammatory drugs (NSAIDs) use ( $<3$ times/week vs. $\geq 3$ times/week), BMI $\left(<30.0 \mathrm{~kg} / \mathrm{m}^{2}\right.$ vs. $\left.\geq 30.0 \mathrm{~kg} / \mathrm{m}^{2}\right)$, time spent in physical activity (<1hour/week, 2-4 hours/week, and $\geq 5$ hours/week), alcohol consumption ( $<2$ drinks/week, 2-6 drinks/week, and $\geq 7$ drinks/week), and smoking status ( $<100$ cigarettes in their lifetime vs. $\geq 100$ cigarettes in their lifetime). We evaluated age, education, health insurance, family history of CRC, family history of DM, diet, fiber supplements, aspirin, NSAIDs, obesity, alcohol, smoking, and physical activity as potential confounders. Gender was also evaluated as an effect modifier variable and the study center as an adjusting variable.

\subsection{Statistical Analysis}

Sociodemographic, clinical, and lifestyle characteristics in cases and controls were described using frequency distributions for categorical variables and summary measures for quantitative variables. Two-sided tests were used to assess comparability of study groups: the chi-square test or Fisher's exact test was used for categorical variables, and Student's t test or Mann-Whitney test to compare quantitative variables. Unconditional logistic regression models were used to estimate the OR with $95 \%$ confidence of CRN, colorectal adenomas, and CRC location in relation to type $2 \mathrm{DM}$ while controlling for demographic characteristics, lifestyle factors, and medical history. Comparisons between DM and colorectal subsite included proximal and distal colon location. Potential confounding variables were selected for assessment a priori on the basis of their hypothesized association with DM and CRN. The presence of a confounder was empirically assessed by entering potential covariates into a logistic regression model one at a time and comparing the adjusted and unadjusted ORs. The final models included covariates (study center, family history of DM, and age) that reached statistical significance using the change-in-estimate model $^{15}$ (variables that changed the point estimate (OR) by $10 \%$ or more in either direction). Lastly, we assessed potential interactions between relevant variables. We examined interactions between sex and DM to assess the findings of sex-specific logistic regression models. Significant interactions by sex were observed; logistic models are shown separately for men and women. Statistical analyses were performed using Stata 10.0 (Stata Corp.), SPSS 17.0 (SPSS Inc.), and Epi Info ${ }^{\mathrm{TM}} 7$ (Centers for Disease Control and Prevention). 


\section{Results}

\subsection{CRN and Lifestyle Variables}

Socio-demographic characteristics in CRN cases and controls are presented in Table 1. CRN cases and controls were similar with regards to age, marital status, healthcare insurance status, and having family history of DM or CRC. Men with CRN had a lower education level, less than a high school degree, $(40.0 \%$ vs. $16.8 \%$, $\mathrm{p}<0.001)$ compared to controls.

Associations between CRN and lifestyle variables are described in Table 2. Increased odds of CRN was observed among women who reported dark green leafy vegetable intake $\geq 5$ times/week compared to women that consumed dark green leafy vegetables $\leq 1$ time/week $(\mathrm{OR}=3.30,95 \% \mathrm{CI}: 1.22-8.90)$. On the other hand, men who reported aspirin use $\geq 3$ times per week had a marginally lower odds ( $\mathrm{OR}=0.51,95 \% \mathrm{CI}: 0.25-1.04, \mathrm{p}=0.06)$ of $\mathrm{CRN}$ than men who did not report regular aspirin use. Women who reported use of NSAIDs $\geq 3$ times per week had a significant lower odds ( $\mathrm{OR}=0.21,95 \% \mathrm{CI}$ : $0.07-0.61, \mathrm{p}=0.002)$ of CRN than women who did not report regular NSAIDs use. There were no significant associations between CRN and reported fruit intake, meat intake, use of fiber supplements, BMI, physical activity, alcohol consumption, or smoking (Table 2).

\subsection{CRN and type 2 DM}

Associations between CRN and type 2 DM were assessed while controlling for study center, family history of DM, and age. Women with type 2 DM were 2.74 (95\% CI: 0.94-7.99; $\mathrm{p}=0.064$ ) times more likely to have CRN than women without type $2 \mathrm{DM}$. Similarly, a marginal increased odds of CRC was observed for women with type 2 DM compared with those without DM (OR $=2.92,95 \%$ CI: 0.98-8.75; $\mathrm{p}=0.055)$. However, there were no significant associations between type $2 \mathrm{DM}$ and CRN among men.

\subsection{CRN subsite and type $2 \mathrm{DM}$}

Associations between type 2 DM with CRN and CRC subsite (proximal vs. distal colon location) were also assessed (Table 3 ). Women with type $2 \mathrm{DM}$ were significantly more likely to present with proximal CRN compared to controls (OR $=4.83,95 \%$ CI: $1.25-$ 18.58). Similarly, women with type $2 \mathrm{DM}$ had significantly greater odds of having proximal CRC compared to those without DM ( $\mathrm{OR}=7.19,95 \%$ CI: $1.44-35.96)$. However, no significant associations between CRN location and type $2 \mathrm{DM}$ were observed in men.

\section{Discussion}

Associations between type $2 \mathrm{DM}$ and CRN have not been well studied in Hispanics. The present study assessed the association between type 2 DM and CRN among Hispanics, an ethnic minority at high risk for type $2 \mathrm{DM}$. Increased odds of CRN was observed among women with type $2 \mathrm{DM}$, but not among men. Women with type $2 \mathrm{DM}$ were also found to be likely to present with proximal CRN compared to controls.

Significant gender-specific associations between DM and increased risk of CRC have been reported with conflicting results. In a meta-analysis of 14 studies, a significant association between DM and an increased risk for colon cancer was reported (summary RR=1.38, 95\% 
CI: $1.26-1.51) .{ }^{16} \mathrm{DM}$ was found to be associated with increased risk of rectal cancer (summary RR $=1.20,95 \%$ CI: 1.09-1.31) in 12 studies. The association between DM and colon cancer was observed for both men (summary RR $=1.43,95 \%$ CI: $1.30-1.57 ; \mathrm{n}=11$ studies) and women (summary $\mathrm{RR}=1.35,95 \% \mathrm{CI}: 1.14-1.53 ; \mathrm{n}=10$ studies). However, the association between DM and rectal cancer was only statistically significant for men (summary RR=1.22, 95\% CI: $1.07-1.40 ; \mathrm{n}=8$ studies) and not for women (summary $\mathrm{RR}=$ 1.09, 95\% CI: $0.99-1.19 ; \mathrm{n}=8$ studies). ${ }^{16}$ In a population-based study, increased risk of CRC among DM individuals ( $\mathrm{OR}=1.42,95 \% \mathrm{CI}$ : $1.25-1.62)$ compared to those without DM was also reported..$^{17}$ The association between type $2 \mathrm{DM}$ and CRC was statistically significant in both men $(\mathrm{OR}=1.36,95 \% \mathrm{CI}: 1.16-1.61)$ and women $(\mathrm{OR}=1.38,95 \% \mathrm{CI}: 1.14-1.67)$. Evaluation of the association between type 2 DM and CRC in 37,001 subjects with DM and 148,004 controls, a significant association was observed for both men ( $\mathrm{HR}=2.03 ; 95 \% \mathrm{CI}$ : 1.68-2.47) and women (HR $=2.17 ; 95 \%$ CI: 1.77-2.67) after adjusting for age, CVD, chronic liver disease, nephropathy, autoimmune disease, and level of urbanization. ${ }^{18}$ Although some studies have failed to demonstrate an association between DM and development of $\mathrm{CRN},{ }^{19}$ our data supports an association between type $2 \mathrm{DM}$ and CRN, but only in women. The mechanisms contributing to the increased risk of CRC in individuals with DM have not been fully elucidated and may be influenced by hormones such as estrogen. Positive associations between endogenous estradiol levels, insulin, and waist circumference and CRC risk in postmenopausal women have been reported. ${ }^{20}$

Significant associations between biological markers for DM and CRN have been reported. The association between adenomatous polyps and glycemic control was analyzed in a diabetic population. ${ }^{21}$ The quality of glycemic control was determined by mean glycosylated hemoglobin (HbA1c) during the year previous to the diagnosis of adenomatous polyps. For each $1 \%$ increase in mean $\mathrm{HbA1c}$, a significant (1.95 times) increase in the number of polyps found during colonoscopy was observed. Similarly, elevated insulin levels have been seen to duplicate the risk of developing CRC in humans. C-peptides, indirect blood markers of insulin resistance, have been found to be significantly associated with $\mathrm{CRC}(\mathrm{RR}=2.7$; 95\% CI: 1.2-6.2) when adjusting for age, smoking status, fasting, BMI, alcohol consumption, vigorous exercise, and use of aspirin. ${ }^{22}$ Elevated insulin levels may promote the growth of colorectal tumors by reducing hepatic production of insulin growth factor binding proteins levels (IGFBPs), increasing levels of insulin growth factor 1 (IGF-1), or by inhibiting apoptosis via the connection to IGF-1 receptor. ${ }^{11,23}$

In addition to the observed trend toward increased odds of CRN among women with type 2 DM, higher odds of CRN in the proximal colon compared to distal colon was also observed. We previously reported the prevalence of CRN among asymptomatic Puerto Ricans and found that CRN was more frequently located in the proximal colon $(67.7 \%) .{ }^{24}$ Similarly, a significant association between DM status and proximal colon cancer was found $(\mathrm{RR}=1.9$; 95\% CI: 1.3-2.6) after adjusting for age, BMI, total energy intake, calcium intake, and vitamin $\mathrm{E}$ intake in a study evaluating the association between DM and CRC in the Iowa Women's Health Study. ${ }^{7}$ Associations between DM and distal colon or rectum were not observed. The biological plausibility of the association between DM and proximal colon location is unclear. ${ }^{25}$ According to Lindblom (2001), a potential mechanism that may contribute to the trend observed for proximal CRN location in DM individuals could be 
microsatellite instability as well as chromosomal instability, which are associated to proximal colon. ${ }^{26}$ In addition, differences between lifestyle risk factors such as obesity, diet, and physical activity may explain the associations found between DM and proximal CRN location. ${ }^{27-29}$

The strength of this study lies in that medical diagnosis of CRN and the clinical-pathological characteristics were documented by medical records including pathology and/or surgery reports. However, our study has some limitations that have to be considered. First, the statistical power is limited due to the sample size. Second, the information collected in the questionnaire was self-reported and may be subject to recall bias. Nevertheless, participants who did report a positive type $2 \mathrm{DM}$ diagnosis were asked to report current medications and/or treatment for DM. Third, sampling controls from hospital records may have introduced a Berkson's bias. However, the cases and controls represented similar populations. Fourth, another limitation might be that our study may be affected by residual confoundings, such as dark green vegetable intake, NSAIDS use and BMI, that were not statistically significant using the change-in-estimate model and were therefore not used to adjust into the multi-variable model.

\section{Conclusions}

In summary, our results suggest increased odds for CRN among Hispanic women with type 2 DM, with predominance for proximal CRN. Given than PRH have a high prevalence of DM and that DM was found to be associated with increased odds to CRN, our results highlight the importance of educating Hispanics about adherence to CRC screening in order to decrease the burden of this disease among this minority population. Future studies could evaluate the molecular pathways contributing to higher risk of CRN in Hispanics with DM.

\section{Supplementary Material}

Refer to Web version on PubMed Central for supplementary material.

\section{Acknowledgments}

Funding: National Institute on Minority Health Disparities Award Number 8U54MD 007587-03 and U54MD007587; NCI Award Number 5K22CA115913-03, R21CA167220-01, 5R03CA130034-02, and U54CA096297/CA096300; Center for Collaborative Research in Health Disparities RCMI Award Number G12MD007600.

This work was partially supported by the Research and Development Service, the Gastroenterology Department and Department of Veterans Affairs, Caribbean Healthcare System San Juan, P.R.

\section{References}

1. Institute NC. Surveillance, Epidemiology, and End Results Program: SEER Stat Fact Sheets: Colon and Rectum Cancer: Surveillance, Epidemiology, and End Results Program (SEER). 2014.

2. Tortolero-Luna G, Zavala-Zegarra D, Pérez-Ríos N, et al. Cancer in Puerto Rico, 2006-2010. Puerto Rico Central Cancer Registry. 2013

3. CDC. [accessed August 8, 2014.] CfDCaP. Behavioral Risk Factor Surveillance System Survey Data. Available from URL: http://apps.nccd.cdc.gov/brfss/ 
4. Limburg PJ, Vierkant RA, Fredericksen ZS, et al. Clinically confirmed type 2 diabetes mellitus and colorectal cancer risk: a population-based, retrospective cohort study. Am J Gastroenterol. 2006; 101(8):1872-9. [PubMed: 16790032]

5. Khaw KT, Wareham N, Bingham S, Luben R, Welch A, Day N. Preliminary communication: glycated hemoglobin, diabetes, and incident colorectal cancer in men and women: a prospective analysis from the European prospective investigation into cancer-Norfolk study. Cancer Epidemiol Biomarkers Prev. 2004; 13(6):915-9. [PubMed: 15184246]

6. Larsson SC, Orsini N, Wolk A. Diabetes mellitus and risk of colorectal cancer: a meta-analysis. J Natl Cancer Inst. 2005; 97(22):1679-87. [PubMed: 16288121]

7. Limburg PJ, Anderson KE, Johnson TW, et al. Diabetes mellitus and subsite-specific colorectal cancer risks in the Iowa Women's Health Study. Cancer Epidemiol Biomarkers Prev. 2005; 14(1): 133-7. [PubMed: 15668486]

8. Will JC, Galuska DA, Vinicor F, Calle EE. Colorectal cancer: another complication of diabetes mellitus? Am J Epidemiol. 1998; 147(9):816-25. [PubMed: 9583711]

9. Nilsen TI, Vatten LJ. Prospective study of colorectal cancer risk and physical activity, diabetes, blood glucose and BMI: exploring the hyperinsulinaemia hypothesis. Br J Cancer. 2001; 84(3):41722. [PubMed: 11161410]

10. Bowers K, Albanes D, Limburg P, et al. A prospective study of anthropometric and clinical measurements associated with insulin resistance syndrome and colorectal cancer in male smokers. Am J Epidemiol. 2006; 164(7):652-64. [PubMed: 16877536]

11. Giovannucci E, Harlan DM, Archer MC, et al. Diabetes and cancer: a consensus report. CA Cancer J Clin. 2010; 60(4):207-21. [PubMed: 20554718]

12. CDC. [accessed September 14, 2009.] CfDCaP. Behavioral Risk Factor Surveillance System Survey Data. Available from URL: http://apps.nccd.cdc.gov/brfss/display.asp? cat $=$ DB \&yr=2008\&qkey $=1363 \&$ state $=P R$

13. Flood A, Strayer L, Schairer C, Schatzkin A. Diabetes and risk of incident colorectal cancer in a prospective cohort of women. Cancer Causes Control. 2010; 21(8):1277-84. [PubMed: 20383575]

14. Newcomb PA, Baron J, Cotterchio M, et al. Colon Cancer Family Registry: an international resource for studies of the genetic epidemiology of colon cancer. Cancer Epidemiol Biomarkers Prev. 2007; 16(11):2331-43. [PubMed: 17982118]

15. Rothman, K.; Greenland, S.; Lash, T. Modern Epidemiology. 3. Philadelphia, PA: Lippincott Williams \& Wilkins; 2008.

16. Yuhara H, Steinmaus C, Cohen SE, Corley DA, Tei Y, Buffler PA. Is diabetes mellitus an independent risk factor for colon cancer and rectal cancer? Am J Gastroenterol. 2011; 106(11): 1911-21. quiz 22. [PubMed: 21912438]

17. Yang YX, Hennessy S, Lewis JD. Type 2 diabetes mellitus and the risk of colorectal cancer. Clin Gastroenterol Hepatol. 2005; 3(6):587-94. [PubMed: 15952101]

18. Wang JY, Chao TT, Lai CC, et al. Risk of colorectal cancer in type 2 diabetic patients: a population-based cohort study. Jpn J Clin Oncol. 2013; 43(3):258-63. [PubMed: 23288931]

19. Acevedo A, Diaz Y, Perez CM, Garau M, Baron J, Cruz-Correa M. Diabetes Mellitus and Colorectal Neoplasia. J Cancer Ther. 2012; 3(6A):859-65. [PubMed: 23560242]

20. Gunter MJ, Hoover DR, Yu H, et al. Insulin, insulin-like growth factor-I, endogenous estradiol, and risk of colorectal cancer in postmenopausal women. Cancer Res. 2008; 68(1):329-37. [PubMed: 18172327]

21. Siddiqui AA, Maddur H, Naik S, Cryer B. The association of elevated HbA1c on the behavior of adenomatous polyps in patients with type-II diabetes mellitus. Dig Dis Sci. 2008; 53(4):1042-7. [PubMed: 17939046]

22. Ma J, Giovannucci E, Pollak M, et al. A prospective study of plasma C-peptide and colorectal cancer risk in men. J Natl Cancer Inst. 2004; 96(7):546-53. [PubMed: 15069117]

23. Giovannucci E. Insulin, insulin-like growth factors and colon cancer: a review of the evidence. J Nutr. 2001; 131(11 Suppl):3109S-20S. [PubMed: 11694656]

24. Lathroum L, Ramos-Mercado F, Hernandez-Marrero J, Villafana M, Cruz-Correa M. Ethnic and sex disparities in colorectal neoplasia among Hispanic patients undergoing screening colonoscopy. Clin Gastroenterol Hepatol. 2012; 10(9):997-1001. [PubMed: 22542749] 
25. Jeon JY, Jeong DH, Park MG, et al. Impact of diabetes on oncologic outcome of colorectal cancer patients: colon vs. rectal cancer. PLoS One. 2013; 8(2):e55196. [PubMed: 23405123]

26. Lindblom A. Different mechanisms in the tumorigenesis of proximal and distal colon cancers. Curr Opin Oncol. 2001; 13(1):63-9. [PubMed: 11148689]

27. Cho E, Smith-Warner SA, Spiegelman D, et al. Dairy foods, calcium, and colorectal cancer: a pooled analysis of 10 cohort studies. J Natl Cancer Inst. 2004; 96(13):1015-22. [PubMed: 15240785]

28. Larsson SC, Rutegard J, Bergkvist L, Wolk A. Physical activity, obesity, and risk of colon and rectal cancer in a cohort of Swedish men. Eur J Cancer. 2006; 42(15):2590-7. [PubMed: 16914307]

29. Li M, Li JY, Zhao AL, Gu J. Colorectal cancer or colon and rectal cancer? Clinicopathological comparison between colonic and rectal carcinomas. Oncology. 2007; 73(1-2):52-7. [PubMed: 18334831] 


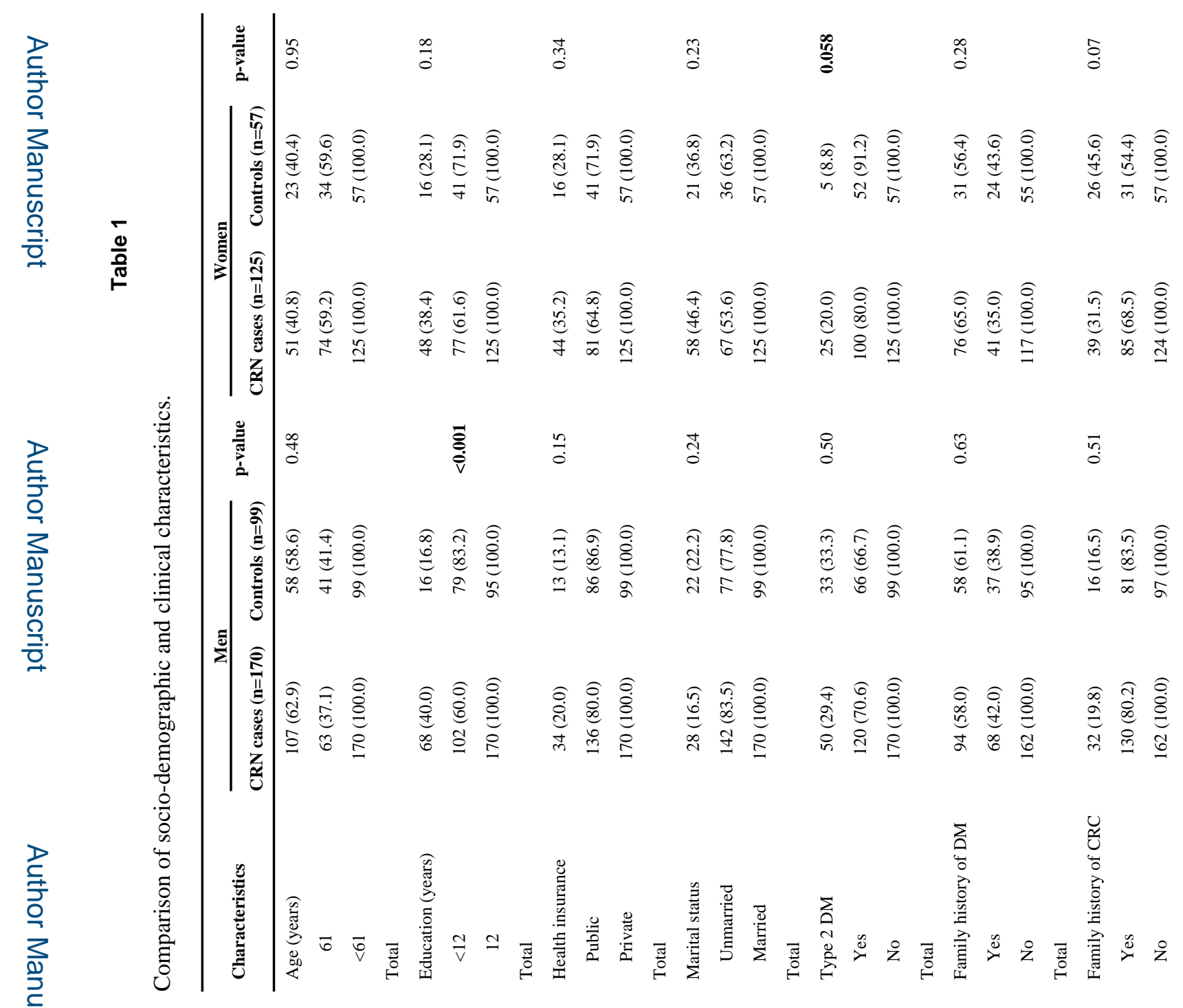

J Diabetes Complications. Author manuscript; available in PMC 2016 May 01. 


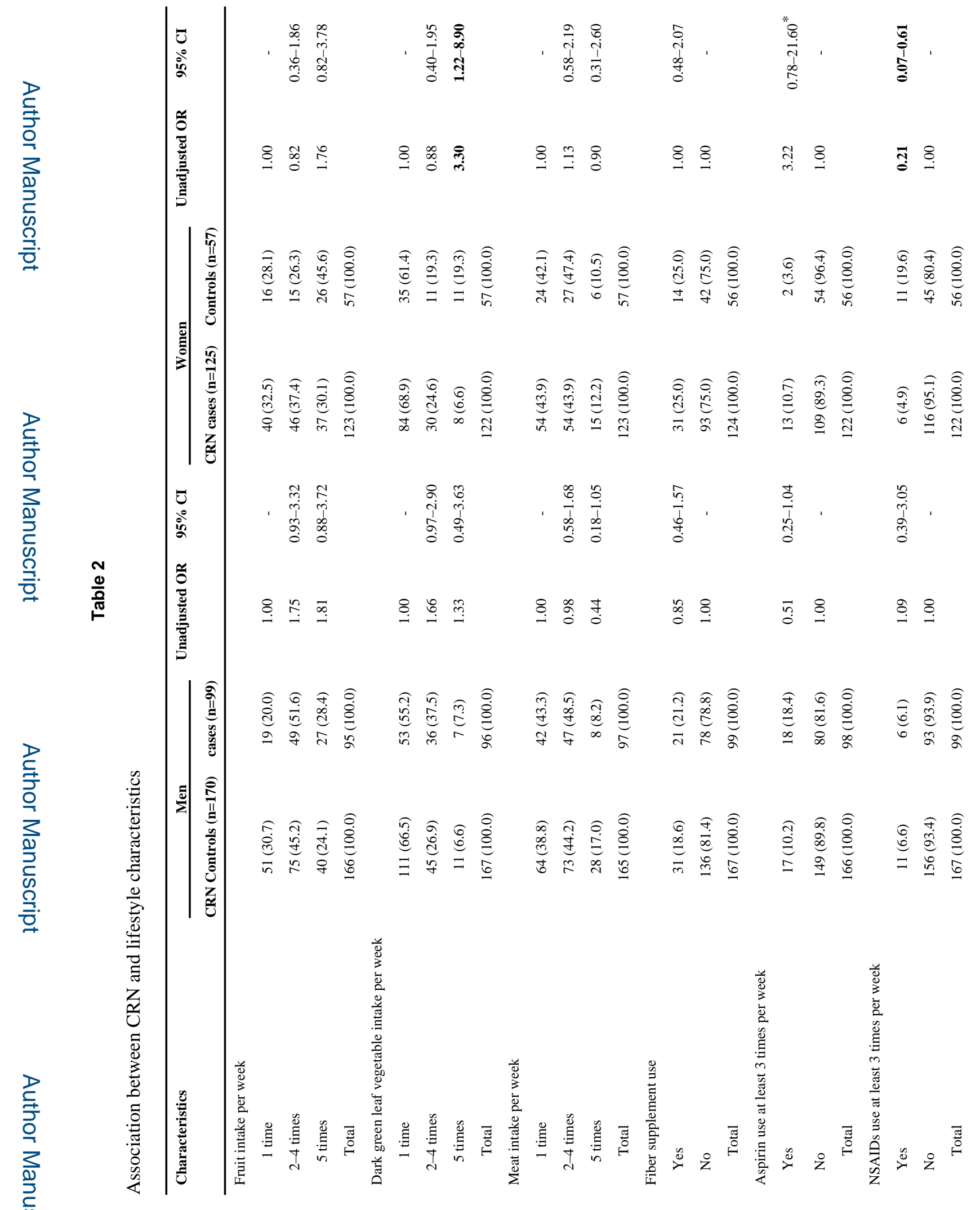

J Diabetes Complications. Author manuscript; available in PMC 2016 May 01. 


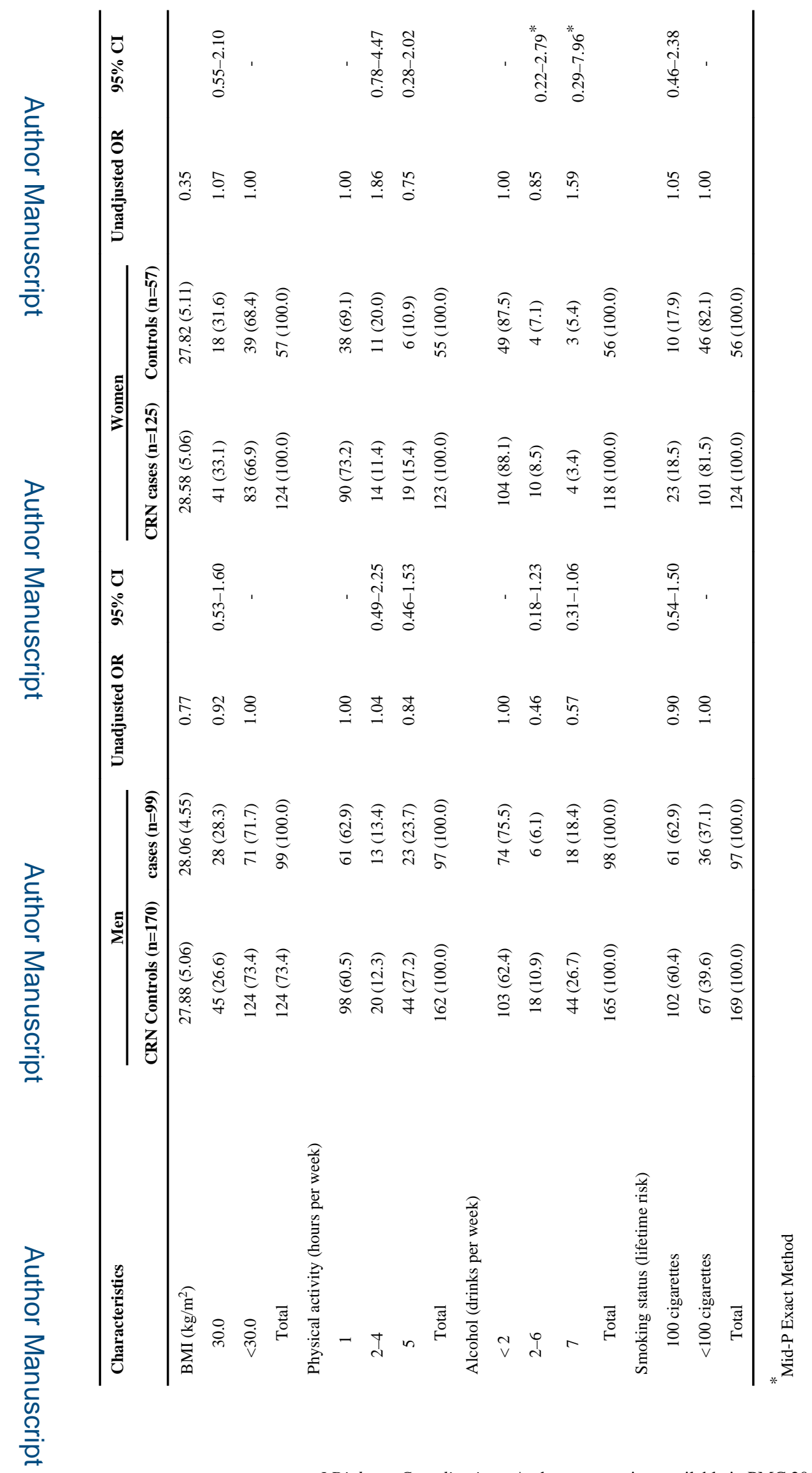

J Diabetes Complications. Author manuscript; available in PMC 2016 May 01. 


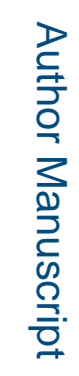

ᄅ

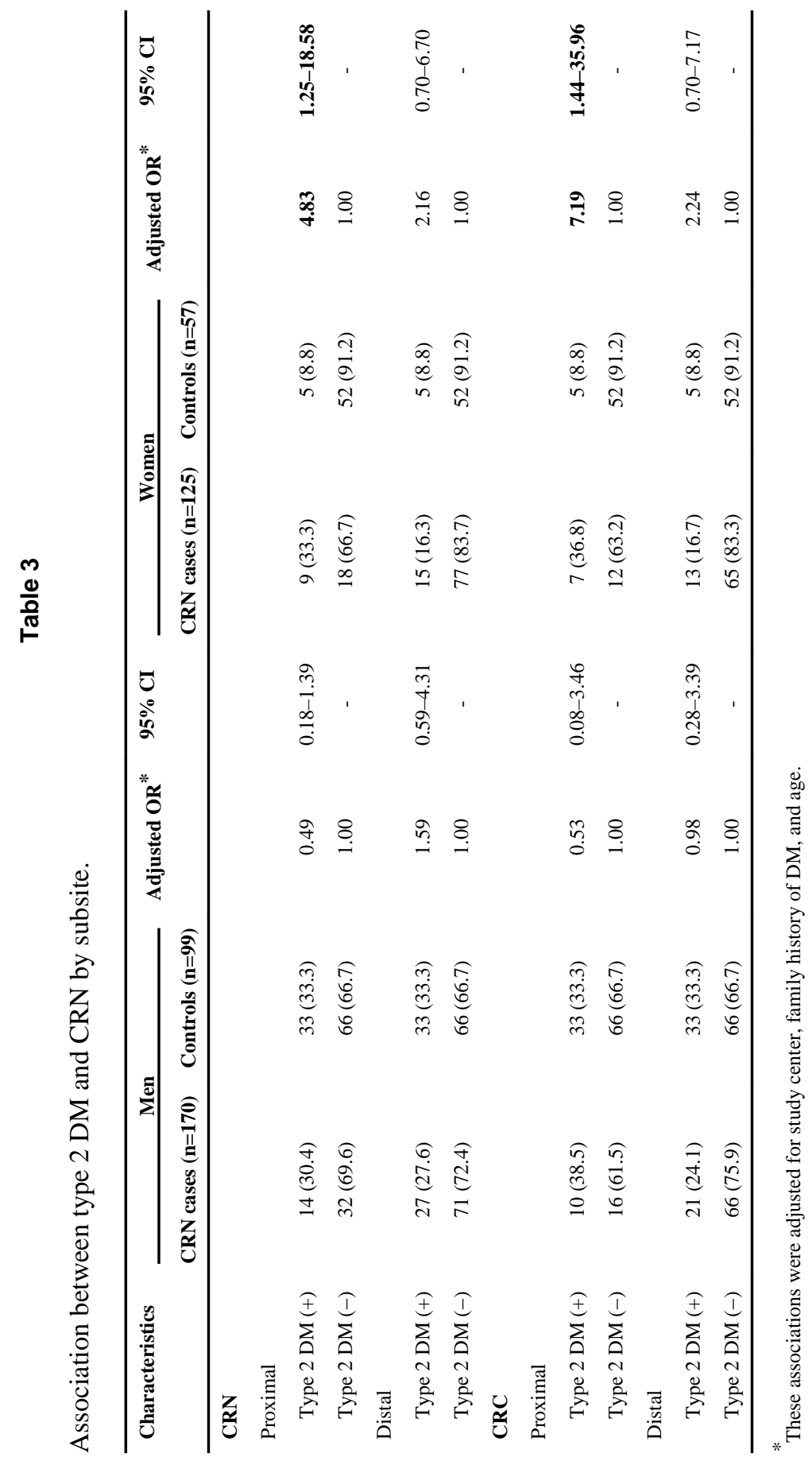

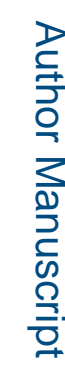

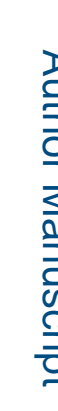

